\title{
Dynamic Fracture Toughness of TaC/CNTs/SiC CMCs Prepared by Spark Plasma Sintering
}

\author{
Qiaoyun Xie and Sylvanus N. Wosu \\ Department of Mechanical Engineering, University of Pittsburgh, Pittsburgh, PA 15261, USA \\ Correspondence should be addressed to Qiaoyun Xie; qiaoyunxie@gmail.com
}

Received 11 September 2015; Revised 14 November 2015; Accepted 19 November 2015

Academic Editor: Fernando Lusquiños

Copyright ( 2015 Q. Xie and S. N. Wosu. This is an open access article distributed under the Creative Commons Attribution License, which permits unrestricted use, distribution, and reproduction in any medium, provided the original work is properly cited.

\begin{abstract}
This study focuses on the fracture toughness of $\mathrm{TaC}$ and carbon nanotubes (CNTs) reinforced SiC ceramic matrix composites (CMCs), prepared by spark plasma sintering (SPS) technique. A high densification of $98.4 \%$ was achieved under the sintering parameter of $133^{\circ} \mathrm{C} / \mathrm{min}, 1800^{\circ} \mathrm{C}$, and $90 \mathrm{MPa}$ pressure. Vickers indentation was employed to measure the indentation toughness on the polished surface of ceramic samples, SEM was applied to directly observe the crack propagation after indentation, and split Hopkinson pressure bar (SHPB) was developed to determine the dynamic fracture toughness within the ceramic samples subjected to an impact in a three-point bending configuration.
\end{abstract}

\section{Introduction}

As carbon nanotubes (CNTs) present excellent Young's modulus, good flexibility, low density, and exceptional electrical and thermal performance in general, they have been considered one of the most promising nanoscale reinforcements for polymers, metals, and ceramics [1-3], among which the CNTs reinforced ceramics with improved fracture toughness have attracted intense global research since they have increasingly been applied in impact related areas such as aerospace and ballistic armors [4]. Accurate understanding and determination of the dynamic fracture toughness at high strain are of significant importance for the assurance of the integrity and safety of structural components subjected to impact loading.

Investigators attempted to extend the quasi-static ASTM standard into dynamic loading range through various high rate bending techniques. The specimens were designed as three- or four-point bending of precracked beams, while the dynamic loading was applied using a modified split Hopkinson pressure bar (SHPB), a drop weight tower, or a modified Charpy tester [5]. Geary et al. [6] studied the dynamic fracture toughness under different strain rates of glass reinforced polymer using three-point bending specimens, and they reported that the dynamic fracture toughness is higher than the static one owing to different failure modes. Samborski and Sadowski [7] compared the static and dynamic fracture toughness values for alumina and magnesia ceramics and investigated the effect of porosity on the fracture toughness and found that the increase of initial porosity reduces the values of both static and dynamic fracture characteristics. Rubio-González et al. [8] tested the dynamic fracture toughness for two composite materials by means of instrumented Hopkinson bar with precracked specimens loaded on a three-point bending configuration. Up to now, there has not been a complete standard to characterize and measure dynamic fracture toughness of ceramic materials owing to both the difficulties in dynamic fracture theory and experimental techniques $[9,10]$.

The purpose of this paper is to develop a better understanding of the fracture toughness of ceramic composite in impact from quasi-static to dynamic, as well as the possibility of toughening with CNTs reinforced silicon carbide ceramics. In this study, $\mathrm{TaC}$ and $\mathrm{CNTs}$ reinforced $\mathrm{SiC}$ ceramic matrix composites (CMCs) were prepared by a two-stage spark plasma sintering (SPS) technique, and Vickers indentation 
TABLE 1: Specification of materials used.

\begin{tabular}{lccc}
\hline Material & $\begin{array}{c}\text { Density } \\
\left(\mathrm{g} / \mathrm{cm}^{3}\right)\end{array}$ & Average size & Purity, \% \\
\hline $\mathrm{SiC}$ & 3.216 & $800 \mathrm{~nm}$ & $>99$ \\
$\mathrm{TaC}$ & 13.9 & $1000 \mathrm{~nm}$ & $>99$ \\
$\mathrm{MWCNTs}$ & 2.1 & Do $<20 \mathrm{~nm}, \mathrm{Di}: 4 \mathrm{~nm}, \mathrm{~L}: 1-12 \mathrm{um}$ & $>99 \mathrm{wt}$ \\
$\mathrm{B}_{4} \mathrm{C}$ & 2.51 & $45-55 \mathrm{~nm}$ & $>99$ \\
\hline
\end{tabular}

was employed to measure the indentation toughness on the polished surface of ceramic samples, SEM to directly observe the crack propagation after indentation, and SHPB to determine the dynamic fracture toughness within the ceramic samples subjected to an impact in a three-point bending configuration. The work is novel in that the SHPB apparatus allowed accurate measurement of velocity, force, and energy absorption information during the entire impact duration using the recorded incident, reflected, and transmitted stress waves.

\section{Experimental}

2.1. Powder Preparation for SPS. Commercially available high purity submicron beta $\mathrm{SiC}$ powder, $\mathrm{TaC}$ powder, and $\mathrm{B}_{4} \mathrm{C}$ powder were obtained from US Research Nanomaterials Inc., TX, USA. The multiwalled CNTs employed in this study were obtained from Cheap Tubes Inc., VT, USA. More detailed information of the materials used is listed in Table 1 .

The high covalency of $\mathrm{Si}-\mathrm{C}$ bonds and the low selfdiffusion coefficient of $\mathrm{SiC}$ make densification more difficult. To obtain high density sintering $\mathrm{SiC}$ ceramics, mechanisms that can provide the high amount of energy required for the formation and migration of defects are necessary. $\mathrm{B}_{4} \mathrm{C}$ has been reported in the literature $[11,12]$ as an effective sintering aid to eliminate surface oxides presented in $\mathrm{SiC}$ and $\mathrm{TaC}$ particles toward enhancing densification.

It is critical that the CNTs are distributed uniformly into the matrix. Being the most popular technique today, ultrasonic agitation exposes CNTs to ultrasonic waves and transfers shear forces to individual nanotubes which break them from agglomerates $[13,14]$. First, the nonfunctionalized multiwalled carbon nanotubes were added to the ethanol solvent at a concentration of $1.0 \%$ weight per volume, forming a nanotube suspension, and then ultrasonicated for $45 \mathrm{~min}$ to disperse the nanotubes in the ethanol solvent. Subsequently, appropriate weight percentages of $\mathrm{SiC}, \mathrm{B}_{4} \mathrm{C}$, and $\mathrm{TaC}$ were added and fully stirred by ultrasonication again for $90 \mathrm{~min}$. In the last step, the homogeneous suspension was baked for about 10 hours until completely dry and then crushed to form the $\mathrm{SiC}-4 \mathrm{wt} \% \mathrm{CNTs}-4 \mathrm{wt} \% \mathrm{TaC}-1 \mathrm{wt} \% \mathrm{~B}_{4} \mathrm{C}$ powder. SEM image of the as-mixed powder is shown in Figures 1 (a) and 1(b). It can be seen clearly in Figures 1(c) and 1(d) that CNTs were well distributed within the mixed powders.

2.2. Fabrication of SiC Based CMCs by SPS. The DR. SINTER SPS system from Fuji Electronic Industrial Co., Ltd., was utilized to sinter the $\mathrm{SiC}$ ceramic composite samples at California Nanotechnologies (Cal Nano) (Cerritos, CA, USA). Silicon carbide composites (SiC-4 wt\% CNTs-4 wt\% $\mathrm{TaC}-1 \mathrm{wt} \% \quad \mathrm{~B}_{4} \mathrm{C}$ ) were held in between the graphite die and punch and sintered in vacuum by SPS. A two-stage sintering technique was developed to achieve the improved densification and mechanical properties, which involved holding samples for certain durations before reaching the final temperature and pressure. This is due to the concern that one-stage heating temperature and loading pressure would develop temperature gradients at the cross sections of samples, which degrades the densification and mechanical properties $[15,16]$. Thus, a heating rate of $133^{\circ} \mathrm{C} / \mathrm{min}$ was used for the first $9 \mathrm{~min}$ till the temperature reached $1200^{\circ} \mathrm{C}$, and then with a holding time of $3 \mathrm{~min}$ for increasing the pressure, temperature was adjusted to $1800^{\circ} \mathrm{C}$ and maintained for $10 \mathrm{~min}$. A two-stage uniaxial pressure with an initial value of $30 \mathrm{MPa}$ was applied during the first stage of temperature climbing, and the maximum value of $90 \mathrm{MPa}$ was reached before the second stage of temperature increasing through the upper electrode by the hydraulic system. The sintering behavior was monitored by measuring the change in axial displacement of the punch. The current and loading were ceased at the end of sample soaking time with a total time of $27 \mathrm{~min}$. After cooling down naturally, samples were removed from the die and achieved a high densification of 98.4\% [17].

Backscattered electron images in the SEM display compositional contrast resulting from different atomic number elements, while EDS analysis allows one to identify each element and its intensity as presented in Figure 2. It can be identified that the grayish white phase is $\mathrm{SiC}$, while the white and dark phases are $\mathrm{TaC}$ and $\mathrm{B}_{4} \mathrm{C}$, respectively.

2.3. Vickers Indentation. Vickers indentation was conducted by the Microindentation Tester LM800 (Leco, MI, USA), with a diamond in the form of a square-based pyramid indenter. The indentation test was carried out at a load of $2 \mathrm{kgf}$, and ten indents were created. The Vickers hardness $\mathrm{HV}$ is calculated as the mean contact pressure, that is, load divided by projected area:

$$
\mathrm{HV}=\frac{F}{A} \approx \frac{1.854 F}{d^{2}},
$$

where $F$ is the loading force, $A$ is the indentation area, and $d$ is the average length of the diagonal left by the indenter. To avoid border effects the thickness of the sample should be at least 10 times bigger than the indentation depth [18].

For brittle ceramic materials, indentation toughness (IT) can be calculated according to Anstis et al. [19]:

$$
\mathrm{IT}=0.016 \sqrt{\frac{E}{\mathrm{HV}}} \frac{F}{c^{3 / 2}},
$$

where $E$ is Young's modulus and $c$ is the crack length from the impression center (Figure 3). The crack length used in (2) is the average of all four cracks from the indentation. The crack length is measured using SEM (Philips XL 30 FEG).

2.4. Dynamic Fracture Toughness Setup. The ASTM C142110 three-point bending test is one of the simplest methods 


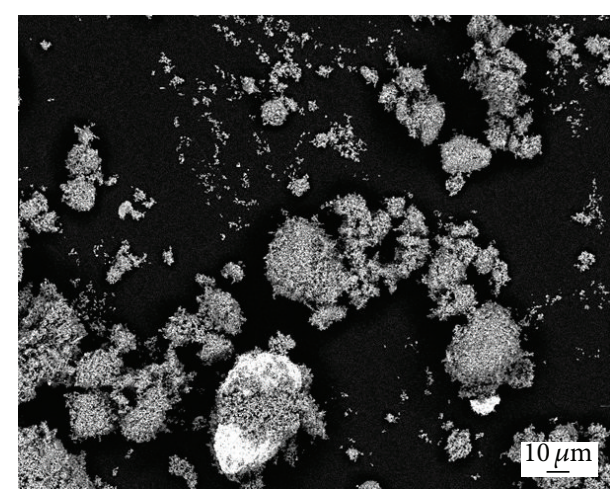

(a)



(c)

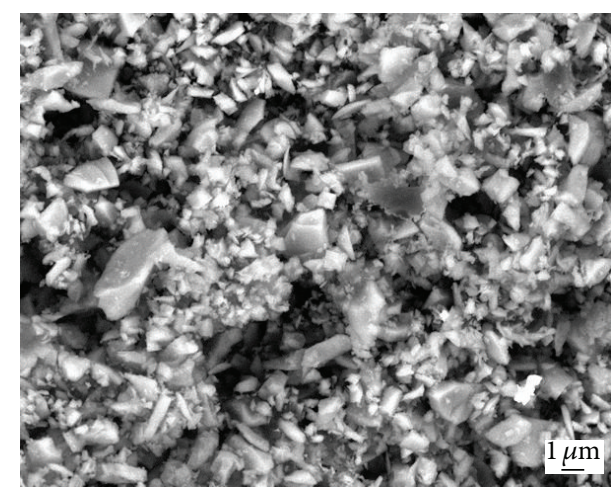

(b)

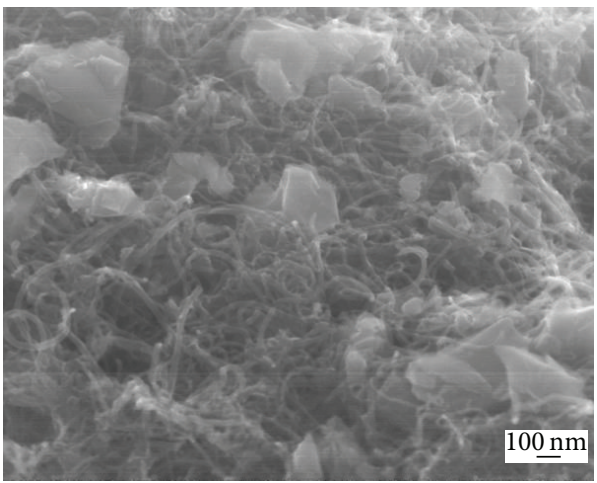

(d)

FIGURE 1: SEM images showing the powder mixtures of SiC- 4 wt $\%$ CNTs- $4 \mathrm{wt} \% \mathrm{TaC}-1 \mathrm{wt} \% \mathrm{~B}_{4} \mathrm{C}$.

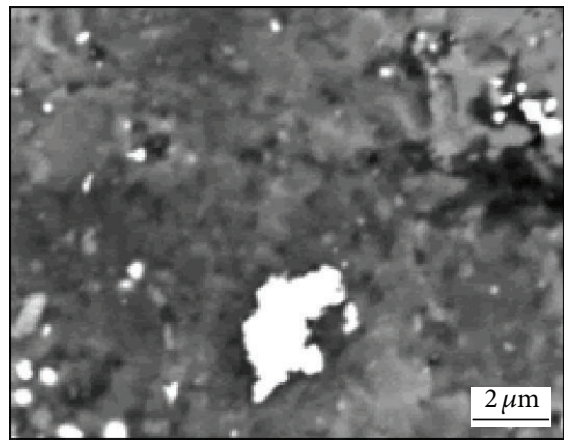



B K

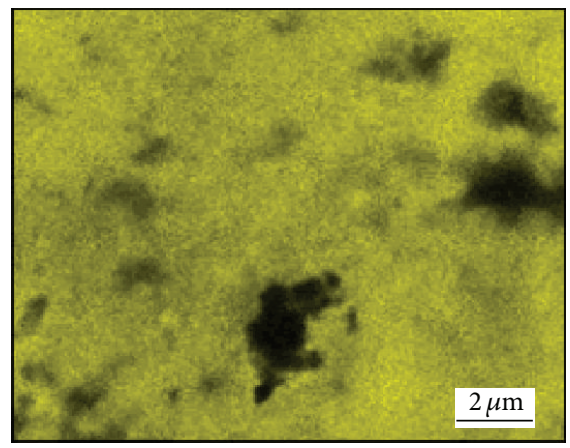

Si K

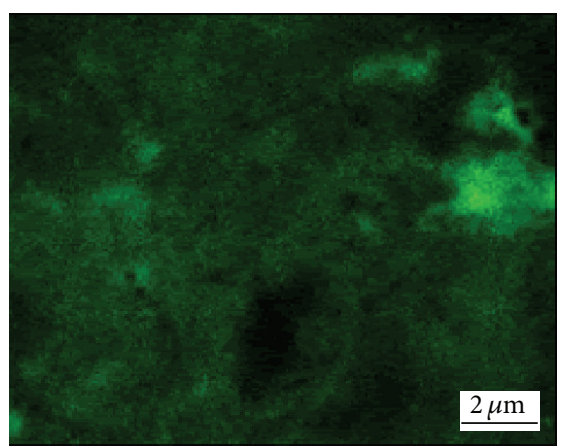

C K

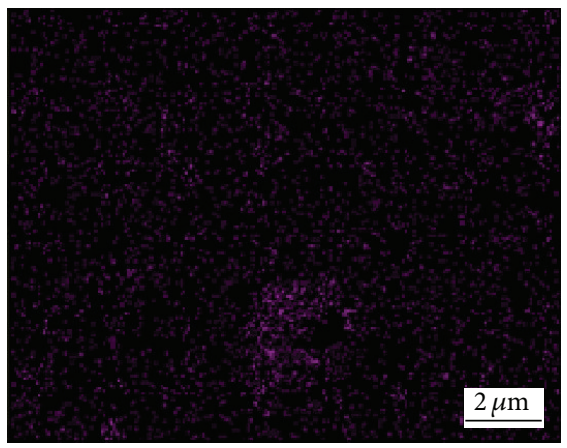

Ta L

FIGURE 2: EDS mapping of the distribution and intensity of elements over the scanned area of the sintered specimen. 


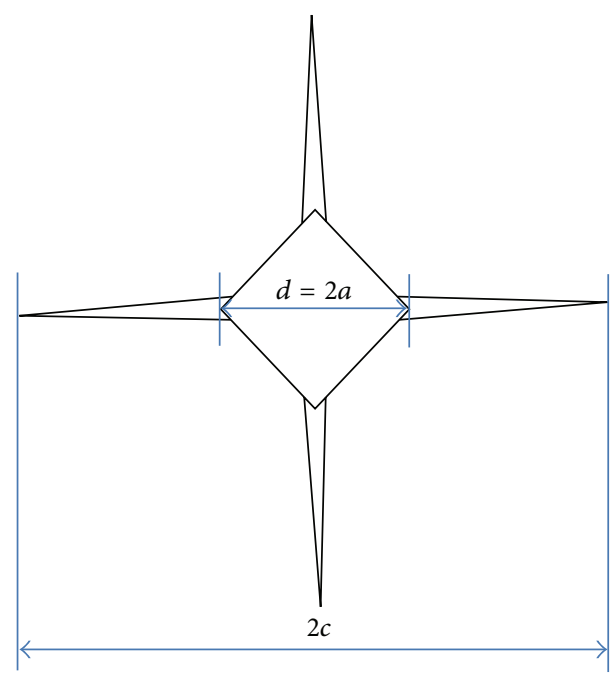

FIGURE 3: Crack created by the Vickers indenter.

for determination of the fracture characteristics of advanced ceramics at ambient temperature. The specimens were prepared according to the precracked beam method with a straight-through precrack created in the beam via bridgeflexure technique. The most important issue among those interested in plane strain fracture toughness testing is the specimen size required for a valid $K_{I C}$ test. The precrack should be less than $0.10 \mathrm{~mm}$ in thickness and should have a normalized crack size within the following range $0.12 \leq$ $a / W \leq 0.30$. As the specimens used in this study are very brittle, no further fatigue crack is induced beyond the precrack because the brittle crack may initiate from the highly stress-concentrated area at the notch tip. For three-point fixtures, choose the outer support span such that $4 \leq S_{0} / W \leq$ 10. The details of the test specimen as well as the three-point fixtures are given in Figure 4.

The dynamic experiment of fracture toughness testing was carried out on a modified SHPB with a deformable pulse shaper to obtain the dynamic equilibrium and constant loading rate [20]. Upon impacting by the striker bar, the plastic deformation of the pulse shaper continuously increases its effective diameter, which allows a correspondingly increasing momentum transfer from the striker bar to the incident bar, thus generating an incident pulse with increasing amplitude. This incident waveform can be tuned by varying the pulse shaper material and dimensions. In this research, an annealed copper disk (3.2 mm diameter $\times 3.2 \mathrm{~mm}$ thickness $)$ was placed at the impact end of the incident bar to tune the waveform. The three-point fixtures were glued on the barspecimen ends. A small amount of preloading was necessary to hold the specimen in position between the fixtures, which was achieved by two rubber bands tensioning the two bars, close on the specimen. A schematic of the modified SHPB experimental setup is shown in Figure 5.

As the experiment was designed in such a way that the specimen deformed under dynamic equilibrium at a nearly constant loading rate, the dynamic fracture toughness could be evaluated using the quasi-static method expression:

$$
K_{I C}=f\left(\frac{a}{W}\right)\left[\frac{P_{\max } S_{0} 10^{-6}}{B W^{3 / 2}}\right]\left[\frac{3(a / W)^{1 / 2}}{2(1-a / W)^{3 / 2}}\right],
$$

where

$$
\begin{aligned}
& f\left(\frac{a}{W}\right) \\
& =\frac{1.99-(a / W)(1-a / W)\left[2.15-3.93(a / W)+2.7(a / W)^{2}\right]}{1+2(a / W)},
\end{aligned}
$$

$P_{\max }$ is the maximal dynamic force, $S_{0}$ is the three-point test fixture outer span, $B$ is the side-to-side dimension of the test specimen, $W$ is the top-to-bottom dimension of the test specimen parallel to the crack length, and $a / W$ is the normalized crack size.

\section{Results}

3.1. Samples Response to the Dynamic Loading. The batches of precracked samples (Figure 6(a) left) made of TaC and CNTs reinforced $\mathrm{SiC}$ composites were tested at different energy impact. A collection of representative specimens, which failed under $770 \mathrm{~mJ}$ impact energy for the three-point dynamic fracture test, are shown in Figures 6(a) and 6(b). The threepoint bending configuration generated mode I fracture. The fracture surface of specimen, shown in Figure 7, presented generally well distributed CNTs between the particles, which indicated that CNTs were well retained during the SPS process.

Figure 8 shows the incident, reflected, and transmitted strain pulses determined from the measured strain signal using appropriate system calibration. The waveform is controlled as a nearly linear ramp and captured at a sample rate of 250.000 samples/sec. The nearly constant slope of the incident and reflected strain wave reveals that the loading rate is nearly constant and the specimen deforms under dynamic equilibrium during the fracture test. The transmitted strain wave is very small due to the extreme mismatch between the rigidity and mechanical impedance between the precracked specimen and the bars.

The strain wave pulses provide information for the complete characterization of the dynamic fracture process. Figure 9 displays the time history of energy absorbed by the three-point bending configuration to develop the cracks. The fracture energy absorption increases with time as crack propagates and then decreases when approaching unstable crack propagation state (after $215 \mu \mathrm{s}$ ). This is because, at this energy, the crack length has more than exceeded the critical crack length at which point the potential energy exceeds the fracturing energy. Thus, the fracture energy absorbed decreases since more energy is released than consumed by the crack growth, and crack propagation is less stable and dissipates less energy during the period of rapid propagation than during initiation.

The variation of force-time curve in Figure 10 shows a nearly constant slope before the loading reaches its peak 
TABLE 2: Summary of results of fracture toughness.

\begin{tabular}{lccccc}
\hline $\begin{array}{l}\text { Impact energy } \\
\left(E_{I}, \mathrm{~mJ}\right)\end{array}$ & $\begin{array}{c}\text { Vickers hardness } \\
(\mathrm{HV}, \mathrm{GPa})\end{array}$ & $\begin{array}{c}\text { Strain rate } \\
(\dot{\varepsilon}, 1 / \mathrm{s})\end{array}$ & $\begin{array}{c}\text { Maximum energy absorbed } \\
\left(\Delta U_{A}, \mathrm{~mJ}\right)\end{array}$ & $\begin{array}{c}\text { Maximum loading force } \\
\left(P_{\max }, \mathrm{N}\right)\end{array}$ & $\begin{array}{c}\text { Fracture toughness } \\
\left(K_{I C}, \mathrm{MPa} \cdot \mathrm{m}^{1 / 2}\right)\end{array}$ \\
\hline Indentation & $24.55 \pm 1.32$ & $/$ & $/$ & $/$ & $3.88 \pm 0.28$ \\
445 & $/$ & 51.0 & 49.2 & 65.4 & $4.71 \pm 0.17$ \\
790 & $/$ & 69.8 & 63.5 & 97.7 & $5.45 \pm 0.14$ \\
1235 & $/$ & 90.4 & 86.1 & 149.8 & $8.36 \pm 0.09$ \\
\hline
\end{tabular}

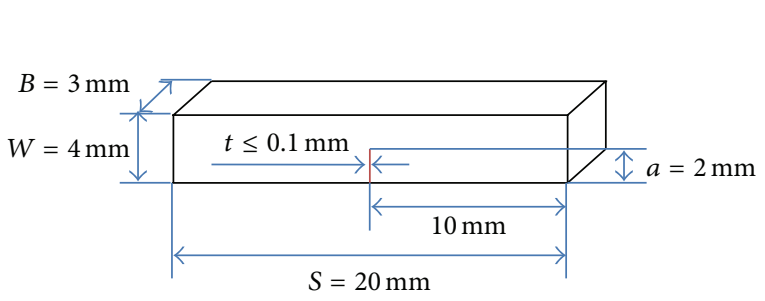

(a)



(b)

Figure 4: (a) Schematic of the ceramic specimen; (b) fixture configuration of the three-point loading.

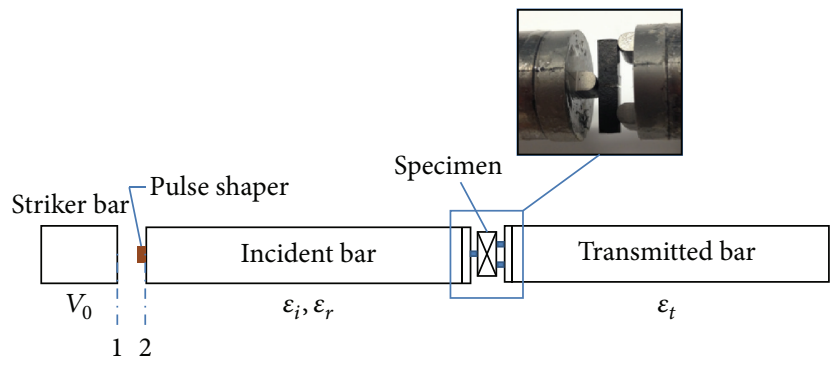

FIGURE 5: Schematic of the modified SHPB setup for fracture toughness.

value, which reveals that the fracturing is under dynamic equilibrium. Therefore, the loading history can be related with the stress intensity factor history near the crack tip. The peak force is assumed as the fracture initiation point, and after that the crack propagates. There are multiple peaks and large oscillation on the force-time curve during crack propagation, owing to the fracture mechanisms, such as crack deflection and crack bridging, which prevent crack propagation.

3.2. Effect of Strain Rate on Fracture Toughness. As impact energy through the striker bar generates strain rate effect on the material properties, such as strength and stiffness, strain rate sensitivity is controlled and defined for fracturing study in this research. The calculated indentation toughness and dynamic fracture toughness, $K_{I C}$, are summarized in Table 2. Figure 11(a) shows the variation of maximum energy absorption generally increased linearly with strain rates.

As the peak force is used to calculate the fracture toughness, $K_{I C}$, according to (3), Figures $11(\mathrm{~b})$ and $11(\mathrm{c})$ present the same nonlinear variation trend for peak loading force and fracture toughness with strain rates. At a lower strain rate of $51.01 / \mathrm{s}$ or as the impact energy was just to initiate and propagate the crack, the $\mathrm{TaC}$ and CNTs reinforced $\mathrm{SiC}$ composites had an average fracture toughness value of $4.71 \mathrm{MPa} \cdot \mathrm{m}^{1 / 2}$. When increasing the strain rate to $69.81 / \mathrm{s}$, the calculated average fracture toughness increased to $5.45 \mathrm{MPa} \cdot \mathrm{m}^{1 / 2}$. Sharply, the average fracture toughness increased to $8.36 \mathrm{MPa} \cdot \mathrm{m}^{1 / 2}$ at a strain rate of $90.41 / \mathrm{s}$, generally increased linearly with strain rates. At a higher strain rate or as more energy is transferred to the system, maximum energy absorbed in the dynamic fracture process increases, which implies that more energy is available in the crack tip to initiate the crack.

\section{Discussion}

Ceramics are brittle at room temperature because the stress required for dislocation movement is higher than the fracture stress and, thus, fracture takes place. The published fracture toughness for $\mathrm{SiC}$ is $3.1 \mathrm{MPa} \cdot \mathrm{m}^{1 / 2}$ [21]. The SPS sintered $\mathrm{TaC} / \mathrm{CNTs} / \mathrm{SiC}$ CMCs exhibit higher fracture toughness compared to the monolith $\mathrm{SiC}$, owing to the combined factors of uniform CNTs distribution, high densification, and improved mechanical performance as reported in our previous work [17]. The structural stability of the CNTs is essential for the fracture toughening to occur. In SPS, the CNTs were subjected to the most severe conditions of heat, pressure, and current but were found to be well retained. As shown in Figure 7, pulled-out CNTs and CNTs networks were both located at the particle boundaries and inside the particles. Figure 12 shows the morphologies of indentation cracks propagated through the SPS sintered $\mathrm{TaC} / \mathrm{CNTs} / \mathrm{SiC}$ composites. It can be seen that the crack propagated with clear deflection, and in some locations it seemed to be stopped by small grains and then get deflected again. A higher magnification SEM micrograph showing the possible toughening mechanism is displayed in Figure 13. The indentation crack interacted with the reinforced $\mathrm{TaC}$ particles and CNTs networks causing shear of the finer particles and 


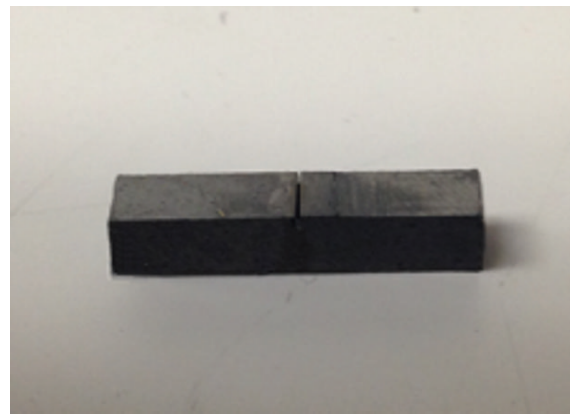

(a)

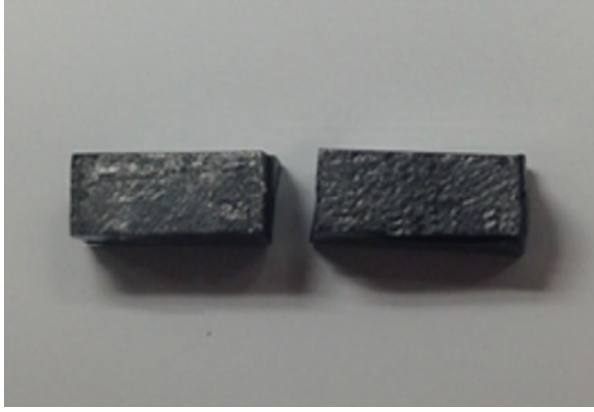

(b)

FIgURE 6: Samples for the dynamic fracture tests: (a) sample before test, (b) sample after test.

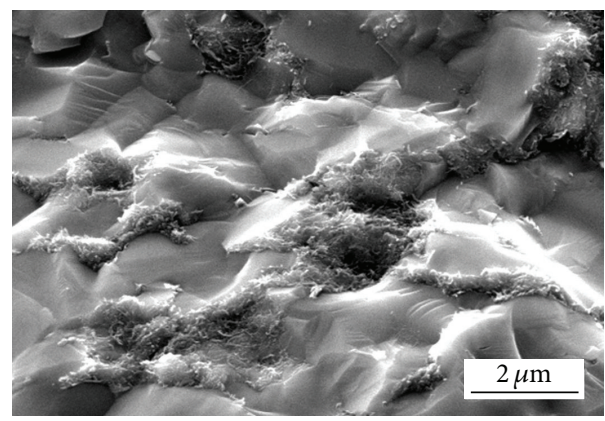

FIGURE 7: SEM micrograph of fracture surfaces of the sample.

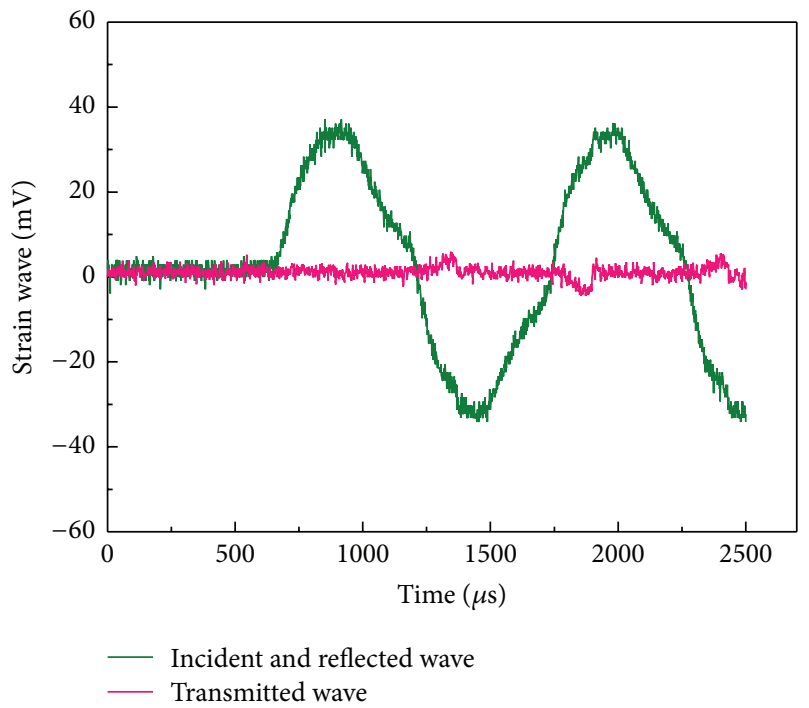

FIGURE 8: Strain waveform for the dynamic fracture test.

crack getting deflected along the interface rather than cutting the coarser particles.

\section{Conclusions}

The dynamic fracture toughness of $\mathrm{TaC}$ and CNTs reinforced $\mathrm{SiC}$ CMCs as a function of loading rate was investigated by the modified SHPB apparatus based on the quasi-static



FIGURE 9: Energy absorption time history for the dynamic fracture test.

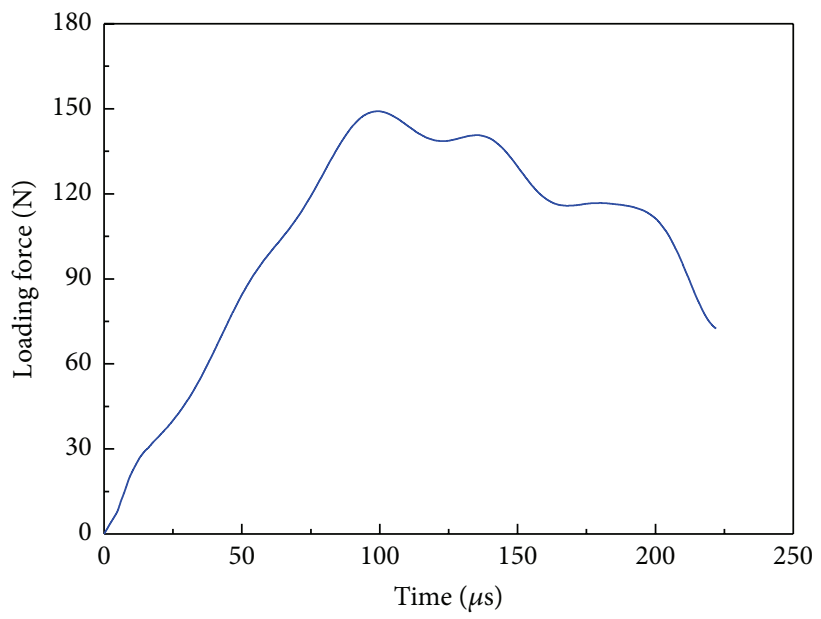

FIGURE 10: Loading force-time history for the dynamic fracture test.

fracture toughness ASTM C1421-10 three-point bending standard for advanced ceramic materials. An annealed copper pulse shaper was successfully applied to SHPB to achieve the dynamic equilibrium and constant loading rate, which 




(a)

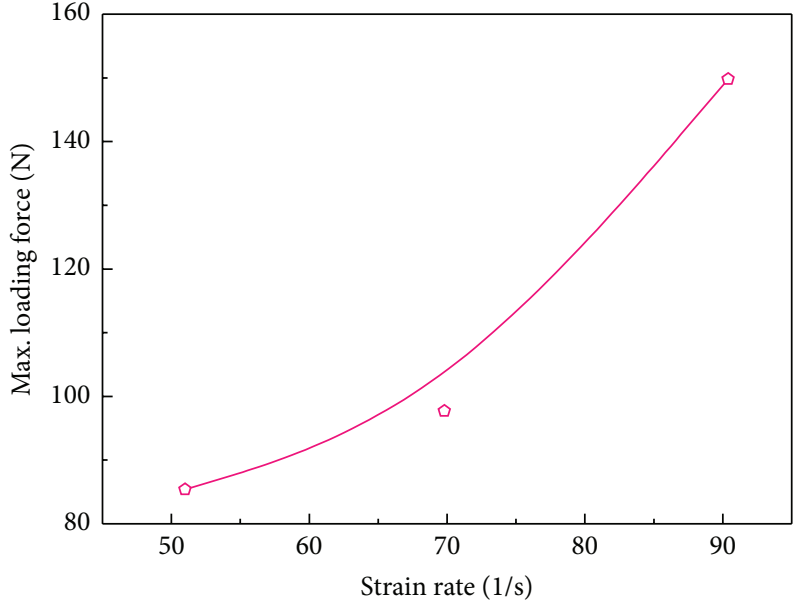

(b)

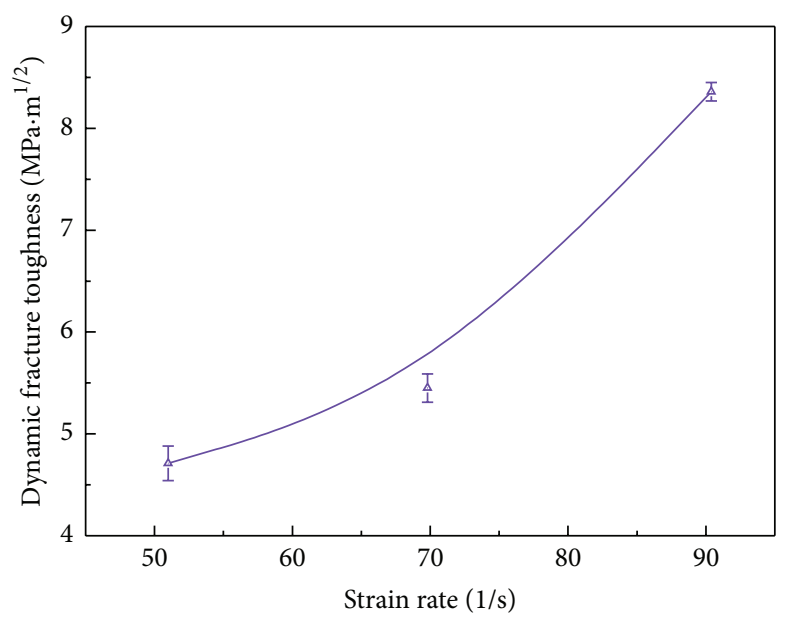

(c)

FIGURE 11: (a) Variation of maximum energy absorbed with strain rate, (b) variation of maximum loading force with strain rate, and (c) variation of fracture toughness with strain rate.

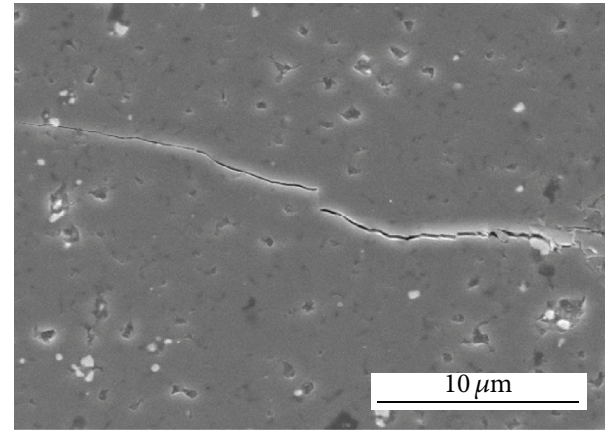

FIGURE 12: SEM image showing crack propagation of $\mathrm{TaC} / \mathrm{CNTs} / \mathrm{SiC}$.

enabled relating the fracture toughness at the crack tip to the far-field peaking loading through quasi-static equation.

The dynamic fracture toughness for $\mathrm{SiC}$ composites was 4.71-8.36 MPa $\cdot \mathrm{m}^{1 / 2}$, which was higher than the indentation

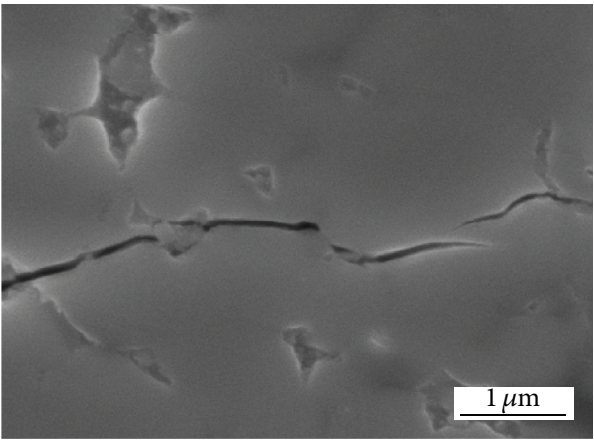

FIGURE 13: Higher magnification showing the toughening mechanism.

toughness of $3.88 \mathrm{MPa} \cdot \mathrm{m}^{1 / 2}$. Variation of strain rate revealed that peak energy absorbed by the system to initiate the crack generally increased linearly with increased strain rates, while peak loading force increased nonlinearly with increased 
strain rates, as the fracture toughness. It was found that the $\mathrm{SiC}$ composites exhibited a more strain rate dependent property for higher strain rate. The TaC and CNTs reinforcements improved the indention toughness of the composites through the toughening mechanisms of crack deflection, particle shearing, and CNTs pullout.

\section{Conflict of Interests}

The authors declare that there is no conflict of interests regarding the publication of this paper.

\section{References}

[1] P. Kim, L. Shi, A. Majumdar, and P. L. McEuen, "Thermal transport measurements of individual multiwalled nanotubes," Physical Review Letters, vol. 87, Article ID 215502, 2001.

[2] R. H. Baughman, A. A. Zakhidov, and W. A. De Heer, "Carbon nanotubes-the route toward applications," Science, vol. 297, no. 5582, pp. 787-792, 2002.

[3] J. Lu, Y.-H. Jian, H.-H. Zhang, H.-L. Shao, and X.-C. Hu, "Preparation and properties of Lyocell/multi-walled carbon nanotube composite fibers," New Carbon Materials, vol. 22, no. 2, pp. 159-164, 2007.

[4] S. Bi, G. Hou, X. Su, Y. Zhang, and F. Guo, "Mechanical properties and oxidation resistance of $\alpha$-alumina/multi-walled carbon nanotube composite ceramics," Materials Science and Engineering A, vol. 528, no. 3, pp. 1596-1601, 2011.

[5] T. Weerasooriya, P. Moy, D. Casem, M. Cheng, and W. Chen, "A four-point bend technique to determine dynamic fracture toughness of ceramics," Journal of the American Ceramic Society, vol. 89, no. 3, pp. 990-995, 2006.

[6] W. Geary, J. Dutton, and D. M. Shuter, “The influence of size effects and dynamic loading on the fracture toughness of commercial GRP materials," Composites Science and Technology, vol. 60, no. 4, pp. 633-638, 2000.

[7] S. Samborski and T. Sadowski, "Dynamic fracture toughness of porous ceramics," Journal of the American Ceramic Society, vol. 93, no. 11, pp. 3607-3609, 2010.

[8] C. Rubio-González, J. A. Gallardo-González, G. Mesmacque, and U. Sanchez-Santana, "Dynamic fracture toughness of prefatigued materials," International Journal of Fatigue, vol. 30, no. 6, pp. 1056-1064, 2008.

[9] W. A. Cutrin, "Stress-strain response of brittle matrix composites," in Encyclopedia of Composites, A. Kelly and C. Zweben, Eds., Elsevier, Amsterdam, The Netherlands, 2000.

[10] M. N. Tamin, Ed., Damage and Fracture of Composite Materials and Structures, vol. 17 of Advanced Structured Materials, Springer, 2012.

[11] X. Zhang, G. E. Hilmas, W. G. Fahrenholtz, and D. M. Deason, "Hot pressing of tantalum carbide with and without sintering additives," Journal of the American Ceramic Society, vol. 90, no. 2, pp. 393-401, 2007.

[12] D. Sciti, L. Silvestroni, S. Guicciardi, D. D. Fabbriche, and A. Bellosi, "Processing, mechanical properties and oxidation behavior of $\mathrm{TaC}$ and $\mathrm{HfC}$ composites containing $15 \mathrm{vol} \% \mathrm{TaSi}_{2}$ or $\mathrm{MoSi}_{2}$," Journal of Materials Research, vol. 24, no. 6, pp. 20562065, 2009.

[13] C. X. Liu and J. W. Choi, "Improved dispersion of carbon nanotubes in polymers at high concentrations," Nanomaterials, vol. 2, no. 4, pp. 329-347, 2012.
[14] G. T. Caneba, C. Dutta, V. Agrawal, and M. Rao, "Novel ultrasonic desertion of carbon nanotube," Journal of Minerals and Materials Characterization and Engineering, vol. 9, no. 3, pp. 165-181, 2010.

[15] D. Jain, K. M. Reddy, A. Mukhopadhyay, and B. Basu, "Achieving uniform microstructure and superior mechanical properties in ultrafine grained $\mathrm{TiB}_{2}-\mathrm{TiSi}_{2}$ composites using innovative multi stage spark plasma sintering," Materials Science and Engineering A, vol. 528, no. 1, pp. 200-207, 2010.

[16] K. Madhav Reddy, N. Kumar, and B. Basu, "Innovative multistage spark plasma sintering to obtain strong and tough ultrafine-grained ceramics," Scripta Materialia, vol. 62, no. 7, pp. 435-438, 2010.

[17] Q. Xie and S. N. Wosu, "Spark plasma sintering of TaC and/or CNTs reinforced SiC CMCs," Journal of Composite Materials, 2015.

[18] ASTM International, "Standard test method for Vickers indentation hardness of advanced ceramic," ASTM C1372-99, ASTM International, West Conshohocken, Pa, USA, 1999.

[19] G. R. Anstis, P. Chantikul, B. R. Lawn, and D. B. Marshall, "A critical evaluation of indentation techniques for measuring fracture toughness: I, direct crack measurements," Journal of the American Ceramic Society, vol. 64, no. 9, pp. 533-538, 1981.

[20] D. J. Frew, M. J. Forrestal, and W. Chen, "Pulse shaping techniques for testing brittle materials with a split Hopkinson pressure bar," Experimental Mechanics, vol. 42, no. 1, pp. 93-106, 2002.

[21] R. G. Munro, "Material properties of a sintered $\alpha$-SiC," Journal of Physical and Chemical Reference Data, vol. 26, no. 5, pp. 11951203, 1997. 

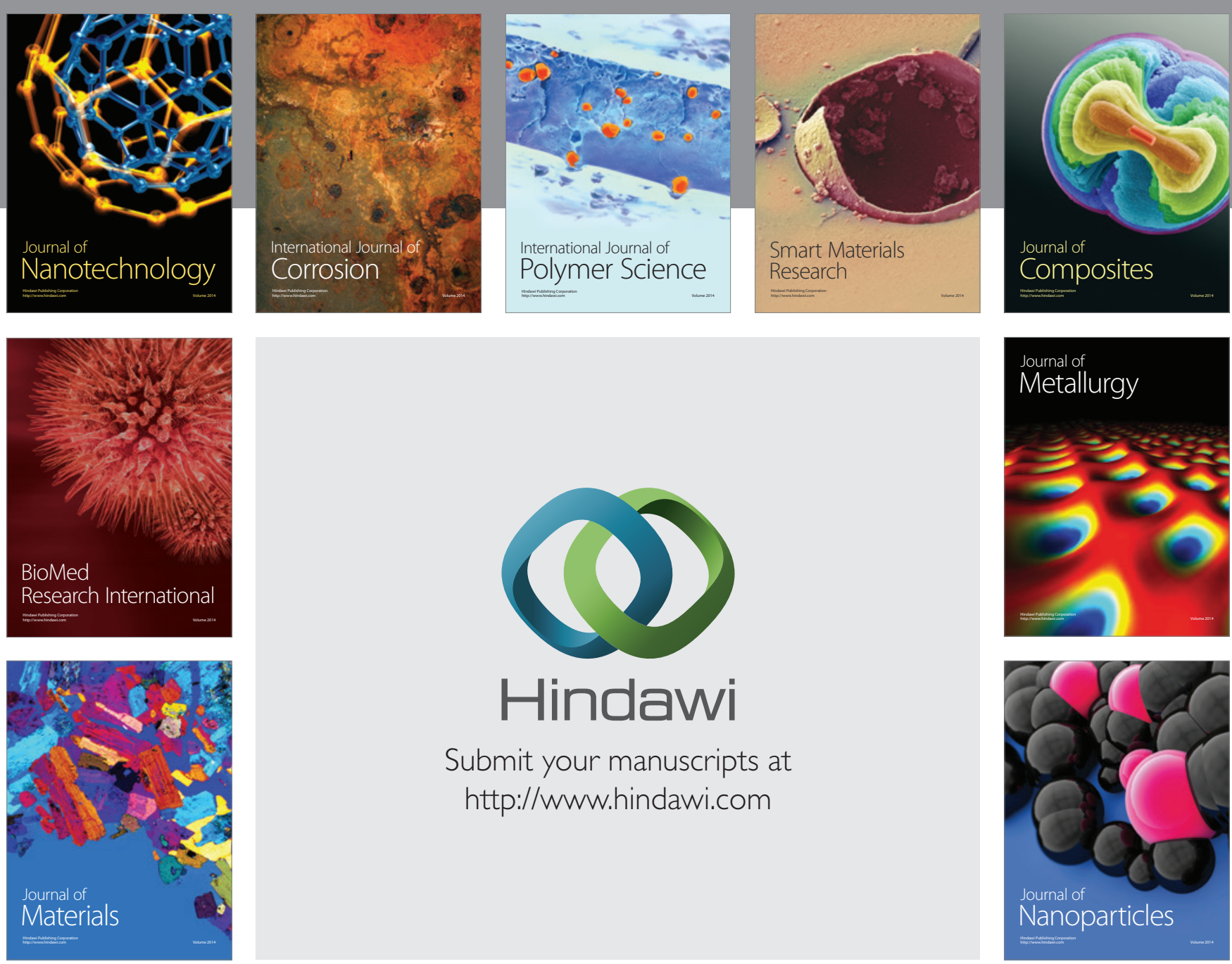

Submit your manuscripts at http://www.hindawi.com


\section{The Scientific World Journal}
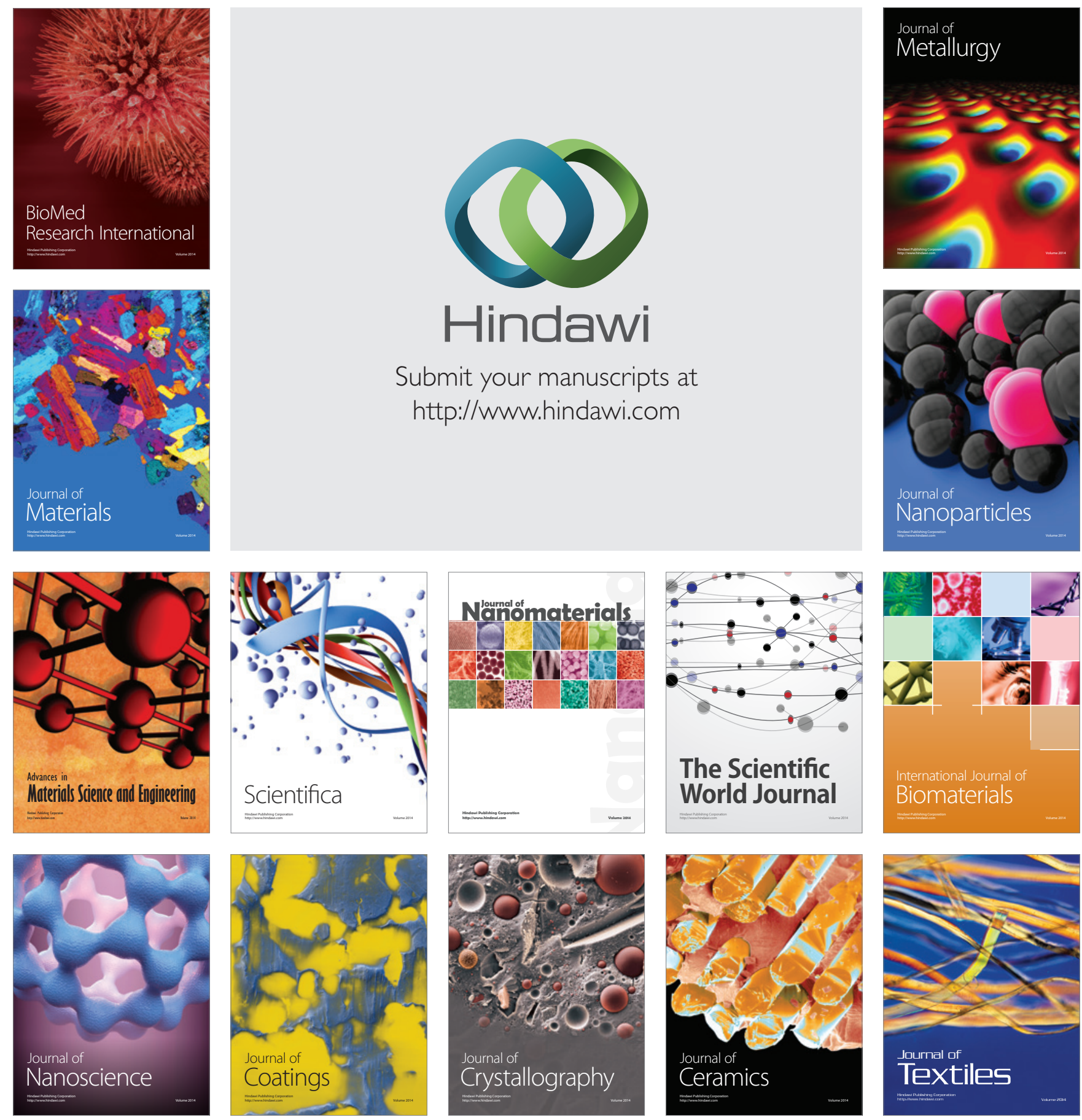